\title{
Dano moral por inadimplemento do contrato
}

\author{
Non-pecuniary damages from breach of contract
}

Pedro Ricardo Serpa*

\section{REFERÊNCIA}

SERPA, Pedro Ricardo. Dano moral por inadimplemento do contrato. Revista da Faculdade de Direito da UFRGS, Porto Alegre, n. 43, p. 293-309, ago. 2020. DOI: https://doi.org/10.22456/0104-6594.95260.

\section{RESUMO}

Um dos temas de Direito Privado que adquiriu maior relevância no passado recente é aquele atinente à responsabilidade civil; podendo-se destacar, desse grande tema, as questões relacionadas aos danos morais. Nesta seara, questão que ainda está a merecer análise mais detida por parte da doutrina nacional é justamente aquela relacionada à indenização por danos morais decorrentes do inadimplemento do contrato.

\section{PALAVRAS-CHAVE}

Responsabilidade Civil. Dano moral. Inadimplemento do contrato.

\section{ABSTRACT}

One of the Private Law's subjects that had increased in relevance in the recent past is the one regarding tort Law, of which one may highlight the matters related to non-pecuniary damages. In that subject, a matter that still deserves a more detailed analysis by the national doctrine is exactly the one related to the non-pecuniary damages from contractual non-performance.

\section{KEYWORDS}

Law of torts. Non-pecuniary damages. Breach of contract.

\section{SUMÁRIO}

1. Introdução. 2. Teorias contrárias à admissibilidade do "dano moral contratual”. 3. Subsídios dogmáticos para a admissão do "dano moral contratual". 4. Requisitos para verificação do "dano moral contratual". 5. "Dano moral contratual" na jurisprudência do Superior Tribunal de Justiça. 6. Conclusões. Referências. Dados da publicação.

\footnotetext{
*** Professor dos cursos de Mestrado Profissional e Pós-Graduação Lato Sensu em Direito Processual Civil, Direitos dos Contratos e Direito Imobiliário, todos da Faculdade Paulista de Direito da Fundação Getúlio Vargas - FGVLaw.
} 


\section{INTRODUÇÃO}

Não há dúvida que, em razão das expressivas modificações tecnológicas, econômicas e culturais pelas quais passou a humanidade nos últimos séculos (resumidas, em dois grandes fenômenos, na Revolução Industrial e na globalização econômica e cultural) - modificações estas que atingiram intensamente a maneira como operam as interações humanas, acarretando um "aumento vertiginoso, crescente e invencível, de momentos e de motivos para colisões de direitos" $"$ - elevou-se ao primeiro patamar de relevância o estudo dos temas relacionados à responsabilidade civil $^{2}$, ramo do Direito Privado que se destina a regular as formas de reparação dos prejuízos injustamente causados nesta dita colisão de direitos. Parece-nos igualmente indubitável que, ao menos em nosso país, nenhum outro tema relacionado à responsabilidade civil recebeu tanta atenção nas últimas décadas quanto aquele atinente aos chamados danos morais ${ }^{3}$.

Entre os inúmeros temas relacionados à indenização por danos morais, um que nos parece merecer análise mais atenta por parte da doutrina pátria é aquele atinente aos ditos "danos morais contratuais", o qual pode se resumir ao seguinte questionamento: é admissível que um ato ilícito perpetrado no âmbito de uma relação jurídica negocial preexistente (i.e., uma relação jurídica circunscrita aos chamados direitos relativos) venha a acarretar prejuízos de ordem não patrimonial ao ofendido, justificando a exigência não apenas dos ordinários danos emergentes e lucros cessantes (de natureza patrimonial), mas, igualmente, o pleito de reparação por danos morais?

Esse questionamento, apesar de seus evidentes reflexos práticos - tanto que encontram eco em centenas de acórdãos proferidos apenas no âmbito do Superior Tribunal de Justiça -, ainda não nos parece ter recebido atenção exaustiva por parte da doutrina nacional ${ }^{4}$.

\footnotetext{
${ }^{1}$ Alvino LIMA, Culpa e Risco, 2a ed., São Paulo, RT, 1998, pág. 16.

${ }^{2}$ Tanto assim que, amparado em conhecida citação de Louis JOSSERAND, Alvino LIMA anunciava que "não há, sem dúvida, assunto mais atual, mais complexo e mais vivo do que o estudo da responsabilidade aquiliana, centro do Direito Civil, ponto nevrálgico de todas as instituições” (Culpa e Risco, op. cit., pág. 15).

${ }^{3}$ Quanto ao ponto, partilha-se das conclusões de Antonio JUNQUEIRA DE AZEVEDO no sentido de que, apesar do intenso debate a respeito do tema, a doutrina ainda não conseguiu pacificar muitos de seus antigos questionamentos (Por Uma Nova Categoria de Dano na Responsabilidade Civil: O Dano Social, in Novos Estudos e Pareceres de Direito Privado, pág. 377).

${ }^{4}$ Fora a obra monográfica de Sidney Hartung BUARQUE (Da Demanda por Dano Moral na Inexecução das Obrigações, $2^{\text {a }}$ ed., Rio de Janeiro, Forense, 2007, passim), a matéria aparece versada em alguns artigos científicos, dos quais se destaca, à guisa de exemplo, aqueles elaborados Mauro FERRANDIN (Dano Moral Contratual, in Jurisprudência Catarinense, ano XXXII, n.110, 2006, págs. 181/207), André Gustavo CORRÊA DE ANDRADE (Dano Moral em Caso de Descumprimento de Obrigação Contratual, in Revista da EMERJ, vol. 8, n. 29, 2005, págs. 134/148), Carolina Souza Cordeiro e Hector Valverde SANTANA (Dano Moral Decorrente de Inadimplemento Contratual de Plano Privado de Assistência à Saúde, in Revista de Direito do Consumidor, ano 20, vol. 80, out.-dez./2011, págs. 213/234), Milena Donato OLIVA (Dano Moral e
} 
Apesar de não ser essa a realidade nacional, a relevância da matéria atinente ao "dano moral contratual" fez dela uma questão de direito posto em alguns dos códigos mais modernos, os quais passaram a admitir a reparabilidade dos danos morais suportados pelo ofendido, ainda que o ilícito tenha sido perpetrado no âmbito de uma relação jurídica negocial preestabelecida.

Seguindo tal linha, o art. 522 do Código Civil Argentino revogado, com redação atualizada pela Lei 17.711/1968, estabelecia que "en los casos de indemnización por responsabilidad contractual el juez podrá condenar al responsable a la reparación del agravio moral que hubiere causado, de acuerdo com la indole del hecho generador de la responsabilidad y circunstancias del caso"; esclarecendo a possibilidade de condenação do ofensor ao pagamento de indenização pelos danos extrapatrimoniais decorrentes de seu inadimplemento contratual, caso assim justifiquem "a índole do ato gerador da responsabilidade e as circunstâncias do caso" $"$.

Da mesma maneira, o art. 1607 do Código Civil da província canadense do Quebec, que entrou em vigor em janeiro de 1994, prescreve que "the creditor ir entitled to damages for bodily, moral or material injury which is an immediate and direct consequence of the debitor's default"; assegurando ao ofendido ampla reparação pelos prejuízos decorrentes do inadimplemento contratual, sem distinguir danos morais, corporais ou materiais.

A despeito de não se tratar de normas de direito positivo, os princípios de unificação do Direito Contratual Europeu ${ }^{6}$ também trazem regras que admitem a reparação do "dano moral contratual".

Nesse sentido, art. 7.4.2 dos Princípios UNIDROIT, sob a rubrica de full compensation (reparação integral, em tradução livre) prescreve que "(1) the aggrieved party is entitled to full compensation for harm sustained as a result of the non-performance. [...] (2) Such harm may be non-pecuniary and includes, for instance, pshysical suffering or emotional distress."

Inadimplemento Contratual nas Relações de Consumo, in Revista de Direito do Consumidor, vol. 93, maio-jun./ 2014, págs. 13/28) e Ana Carolina Nilce Barreira CANDIA (Inadimplemento Contratual e Danos Morais, in Revista de Direito Privado, vol. 80, ago./2017, págs. 57/87). Parece-nos, contudo, que a matéria ainda carece de maior sistematização.

${ }^{5}$ Destaca-se que, no ano de 2014, foi promulgado o Código Civil y Comercial de la Nación Argentina, o qual unificou o regramento da indenização por danos, tratando, em seu art. 1741 da reparação dos danos não patrimoniais de maneira indistinta, sem distinguir se tais prejuízos decorrem do descumprimento de obrigações contratuais ou da violação ao dever genérico de não lesar outrem.

${ }^{6}$ Os quais, nas palavras de Fabíola MORAIS, assemelham-se em certa medida aos Restatements típicos dos Estados Unidos da América e propõem "uma formulação (uma codificação) da lex mercatoria." (Aproximação do Direito Contratual dos Estados-Membros da União Européia, Rio de Janeiro, Renovar, 2007, pág. 190). 
A seu turno, o art. 9:501 dos Principles of European Contract Law (PECL, também denominados de Princípios Lando), estabelece, sob a rubrica right to damages (direito à indenização, em tradução livre), que "(1) the aggrieved party is entitled to damages for loss caused by the other party's non-performance which is not excused under Article 8:108. (2) The loss for which damages are recoverable includes: (a) non-pecuniary loss".

No que se refere ao comércio internacional de mercadorias, muito embora o texto expresso da Convenção de Viena das Nações Unidas sobre Contratos de Compra e Venda Internacional de Mercadorias (CISG, na sigla em inglês) não estabeleça a possibilidade de extração de indenização por danos morais decorrentes do inadimplemento do contrato, aqueles que se debruçaram sobre o tema insistem que a redação do artigo 74 da CISG (o qual, não muito diferente do que seria uma mescla entre os elementos mais importantes contidos nos artigos 402, 403 e 944 do Código Civil Brasileiro, dispõe que: "damages for breach of contract by one party consist of a sum equal to the loss, including loss of profit, suffered by the other party as a consequence of the breach") não é incompatível com tal pleito indenizatório ${ }^{7}$.

Vê-se, assim, que a presente questão está em verdadeira efervescência, tendo merecido inclusive previsão legislativa tanto nos países de nosso continente americano quanto nos países europeus. Razões há, portanto, para que abordemos o tema de maneira mais detida.

\section{TESES CONTRÁRIAS À ADMISSIBILIDADE DO "DANO MORAL CONTRATUAL"}

Em sentido contrário à possibilidade de reparação do "dano moral contratual", enumeram-se alguns argumentos, todos eles de destacada origem formalista ${ }^{8}$.

O primeiro deles, defendido em sede portuguesa por J. M. ANTUNES VARELA ${ }^{9}$, segue no sentido de que o direito posto estabeleceria um regime ressarcitório dúplice $e$ estanque, cindindo de maneira rígida as normas destinadas a regrar a reparação de danos causados no âmbito das relações negociais daquelas cuja finalidade é regrar a reparação de danos perpetrados em casos nos quais não há relação jurídico-negocial preestabelecida. A

\footnotetext{
${ }^{7}$ Sobre o tema, P. SCHLECHTRIEM, Non-Material Damages: Recovery Under CISG?, in Pace International Law Review, n. 19, 2007, págs. 89/102.

${ }^{8}$ Para uma análise dos argumentos a seguir expostos, bem como de outros apresentados na doutrina portuguesa, cfr. R. S. PEREIRA, A Responsabilidade por Danos Não Patrimoniais do Incumprimento das Obrigações no Direito Civil Português, Coimbra, Coimbra, 2009, págs. 250/251.

${ }^{9}$ Das Obrigações em Geral, vol. I, $10^{\mathrm{a}}$ ed., Coimbra, Almedina, 2000, pág. 605, nota 3.
} 
estruturação tópico-legislativa da matéria no Código Civil português traz, de certa maneira, subsídio para esse tipo de argumentação, já que o art. 496o, justamente aquele que estabelece a reparação dos danos não patrimoniais (dispondo, em seu inciso 1, que "na fixação da indemnização deve atender-se aos danos não patrimoniais que, pela sua gravidade, mereçam a tutela do direito"), está inserido em seção especificamente destinada a regulamentar a responsabilidade civil aquiliana (Secção V, Subsecção I, do Capítulo II), e não em seção destinada a regulamentar indistintamente as formas de reparação das duas espécies de responsabilidade (Secção VIII do mesmo capítulo, denominada “obrigação de reparação").

O segundo argumento avesso à indenização do "dano moral contratual", o qual, em certa medida, deriva da premissa a respeito da separação estanque entre os dois regimes ressarcitórios, segue no sentido de que, no âmbito da reparação de danos decorrentes do inadimplemento do contrato, o indispensável caráter patrimonial da prestação (previsto, p. ex., na primeira parte do artigo 1174 do Código Civil italiano, que estabelece que "la prestazione che forma oggetto dell'obbligazione deve essere suscettibile di valutazione economica”) implicaria, de maneira inafastável, que todo prejuízo decorrente da violação a tal prestação tivesse caráter exclusivamente patrimonial ${ }^{10}$.

O terceiro argumento, igualmente defendido por J. M. ANTUNES VARELA ${ }^{11}$, segue no sentido de que a eventual admissibilidade da indenização do "dano moral contratual" faria crescer de maneira incontrolável o número de "demandas frívolas" que tivessem como causa de pedir a ocorrência de danos morais, em fenômeno semelhante ao que, em doutrina nacional, costuma-se denominar de fomento à "indústria do dano moral"12.

\footnotetext{
${ }^{10}$ Era este, como abaixo se verá, o entendimento originalmente esposado pelo STJ a respeito do tema, como se

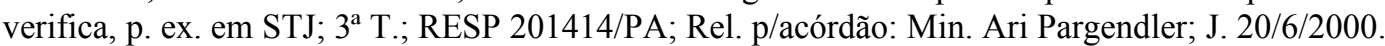

${ }^{11}$ Das Obrigações em Geral, vol. I, 10ª ed., Coimbra, Almedina, 2000, pág. 605, nota 3.

${ }^{12}$ Sobre o conceito de "demandas frívolas" (tida como "a litigância com baixa probabilidade de êxito provocada pelo queixoso”), cfr. M. C. T. PATRÍCIO, Análise Económica da Litigância, Coimbra, Almedina, 2005, pág. 63 e, sobre o sentido da expressão "indústria do dano moral" (em relação à qual se sustenta que, "[m]ais do que a preocupação com o crescimento exponencial do número de ações de indenização por dano moral, o que o uso do termo indústria anuncia é uma frontal rejeição à produção mecânica, algo artificial, com vistas à obtenção de lucro, em uma espécie de abordagem capitalizada de um instituto ontologicamente existencial"), cfr. Anderson SCHREIBER, Novos Paradigmas da Responsabilidade Civil: Da Erosão dos Filtros da Reparação à Diluição dos Danos, São Paulo, Atlas, 2009, pág. 190.
} 


\section{SUBSÍDIOS DOGMÁTICOS PARA A ADMISSÃO DO "DANO MORAL CONTRATUAL"}

Os argumentos acima aventados encontram resistência em fortes subsídios dogmáticos (subsídios estes que, é de se destacar, não são novos, nem tampouco mutuamente excludentes) que, ao menos nos últimos dez anos, têm servido de fundamento para decisões judiciais que admitem o chamado "dano moral contratual".

O primeiro dos subsídios a fundamentar a extração de indenização por danos morais mesmo em casos nos quais se está diante de uma relação negocial preestabelecida é a distinção ponteana, seguida por Marcos Bernardes de MELLO, entre atos ilícitos relativos e atos ilícitos absoluto, também denominados atos ilícitos em sentido estrito ${ }^{13}$.

Enquanto os primeiros (ilícitos relativos) são aqueles perpetrados em violação a deveres resultantes de relações jurídicas típicas de direito relativo (i.e., aquelas relações jurídicas decorrentes de negócio jurídico - em especial, no que concerne ao objeto do presente trabalho, de contratos -, ou, ainda, de ato jurídico em sentido estrito), os últimos (ilícitos absolutos) são aqueles perpetrados quando, entre ofensor e ofendido, (a) não existe relação jurídica prévia; (b), se existe, ela é de direito absoluto (i.e., aquelas nas quais a relação jurídica é estabelecida com sujeito passive indeterminado, o alter, como, p. ex., a relação jurídica resultante do direito de propriedade ou, mais especificamente, aquela resultante dos direitos de personalidade), ou, (c), mesmo quando existe relação de direito relativo (com sujeito passivo determinado, p. ex. aquela relação decorrente de direito de crédito), o ilícito não decorre de quebra do dever objeto da relação, atingindo direito absoluto (como se verifica, p. ex., quando a violação perpetrada no âmbito da relação de direito relativo, atinge direito de propriedade ou, mais especificamente, direito da personalidade).

Tal subsídio poderia ser invocado para justificar a condenação do devedor inadimplente também ao pagamento de indenização por danos morais caso, no âmbito da relação de direito relativo, fosse verificada igualmente a produção de um ato ilícito absoluto, apto a lesar, p. ex., direito da personalidade do qual surgissem consequências prejudiciais tipicamente não patrimoniais ${ }^{14}$.

\footnotetext{
${ }^{13}$ Marcos Bernardes de Mello, Teoria do Fato Jurídico (Plano da Existência), 14a ed., São Paulo, Saraiva, 2007.

${ }^{14}$ É interessante observar que a jurisprudência do E. STJ, especialmente em arestos do Min. Ari Pargendler, já há anos apontava que os prejuízos não materiais decorrem do cometimento dos chamados atos ilícitos absolutos, permitindo a construção de argumento no sentido de que, se o inadimplemento contratual viesse acompanhado de determinadas "circunstâncias especiais", aptas a caracterizar ofensa a direitos da personalidade (i.e., ilícitos absolutos), dele se poderia extrair não apenas a condenação ao pagamento de indenização por danos materiais,
} 
O segundo dos subsídios dogmáticos para viabilizar a admissão do "dano moral contratual" é a compreensão de que, ainda que dotada natureza patrimonial, a prestação pode dizer respeito a um interesse não patrimonial do credor (é esta a dicção da segunda parte do já referido artigo 1174 do Código Civil italiano, que estabelece que a prestação, além de dever ser suscetível de valoração econômica, "deve corrispondere a un interesse, anche non patrimoniale, del creditore") ${ }^{15}$.

Ao se admitir que a prestação também pode dizer respeito a interesses de caráter não patrimonial, abre-se a possibilidade de argumentar que o descumprimento (ou o mal cumprimento) da obrigação contratual também pode acarretar prejuízos que não se restrinjam àqueles de caráter estritamente patrimonial. Admite-se, então, o "dano moral contratual" se o ilícito perpetrado pelo inadimplente extrapola os interesses exclusivamente patrimoniais do credor $^{16}$.

O terceiro subsídio a autorizar a indenização do "dano moral contratual" é a cisão que parcela da doutrina faz quanto ao conceito de dano, distinguindo dano-evento de danoprejuízo $^{17}$. Enquanto o dito dano-evento é a própria lesão a direito subjetivo ou a interesse juridicamente tutelado, o dano-prejuízo é a consequência negativa de caráter mediato decorrente da lesão ao direito subjetivo ou ao interesse juridicamente tutelado.

Tal distinção doutrinária permite delinear uma consequência importantíssima para a admissão do "dano moral contratual”, qual seja, a de que dano-evento e dano-prejuízo não são necessariamente coincidentes, de modo que mesmo a lesão a um direito subjetivo ou interesse

mas, igualmente, por danos morais. Observe-se que, se no julgado de 2001, o entendimento esposado pelo Tribunal parecia bastante restritivo, naquele de 2007 a admissibilidade do "dano moral contratual" parece mais patente: "O dano moral resulta de atos ilícitos absolutos. A conduta inconveniente de um contratante, ou mesmo a inadimplência deste, se resolve em perdas e danos. A não ser assim, qualquer infração contratual implicaria dano moral. É certo que a parte prejudicada pela falta de cumprimento do ajuste fica aborrecida. Mas esse sentimento não ascende ao nível do dano moral." (STJ; 3ª T.; Ag. Reg. no ARESP 303129/GO; Rel.: Min. Ari Pargendler; J. 29/3/2001). "O só inadimplemento contratual, desacompanhado de circunstâncias especiais que caracterizem a ofensa a direitos da personalidade, não acarreta dano moral. $\mathrm{O}$ dano moral resulta de atos ilícitos absolutos. A conduta inconveniente de um contratante, ou mesmo a inadimplência deste, se resolve em perdas e danos. A não ser assim, qualquer infração contratual implicaria dano moral. É certo que a parte prejudicada pela falta de cumprimento do ajuste fica aborrecida. Mas esse sentimento não ascende ao nível do dano moral." (STJ; $3^{\mathrm{a}}$ T.; RESP 704.384/MG; Rel.: Min. Ari Pargendler; J. 18/12/2007).

${ }^{15}$ É justamente este argumento central de diversos doutrinadores que admitem o "dano moral contratual", como, p. ex., André Gustavo Corrêa de ANDRADE, op. cit., pág. 135, R. D. PIZARRO, Daño Moral (Prevención, Reparación, Punición), Buenos Aires, Hammurabi, 1996, pág. 144 e J. M. ITURRASPE e M. A. PIEDECASAS, Responsabilidad Civil y Contratos: Responsabilidad Contractual, Buenos Aires, Rubinzal, 2007, pág. 337.

${ }^{16}$ Nesse sentido, cfr. Milena Donato OLIVA, op. cit., págs. 13/28.

${ }^{17}$ Quanto ao tema, em doutrina nacional, cfr. Antonio JUNQUEIRA DE AZEVEDO, Cadastros de Restrição ao Crédito (Conceito de Dano Moral), in Estudos e Pareceres de Direito Privado, São Paulo, Saraiva, 2004, págs. 289/299 e Silvano José FLUMIGNAN, Dano-Evento e Dano-Prejuízo, Dissertação (Mestrado), São Paulo, USP, 2009, passim. 
de caráter eminentemente patrimonial pode dar ensejo a consequências prejudiciais não patrimoniais ${ }^{18}$.

Apenas a título de exemplo, esse é o caso [i] da destruição de bem patrimonial pelo qual o ofendido nutra afeição (por se tratar de último bem de sua falecida mãe, p. ex.), caso no qual se verifica que a lesão a direito de propriedade (de conteúdo notadamente patrimonial) pode também acarretar prejuízos de ordem não patrimonial, ou, ainda, o caso [ii] da lesão ao direito à integridade física (típico direito de personalidade), a qual, além de acarretar prejuízos de caráter não patrimonial (danos morais e, em certos casos, o chamado dano estético), pode também dar ensejo a graves consequências de ordem patrimonial (p. ex., se o danificado é modelo que precisa de sua bela aparência para o exercício de suas atividades profissionais).

\section{REQUISITOS PARA A VERIFICAÇÃO DO "DANO MORAL CONTRATUAL"}

Apresentados os subsídios dogmáticos que servem de fundamento para a admissão da indenização de danos morais decorrentes do inadimplemento do contrato, passa-se a discorrer a respeito dos requisitos cuja presença deve ser necessariamente verificada para que se possa admitir a condenação aos chamados "danos morais contratuais".

O primeiro desses requisitos é a existência de uma relação jurídica de direito relativo decorrente de negócio jurídico ou ato jurídico em sentido estrito válido (a validade do ato ou negócio jurídico do qual surgirá a relação jurídica de direito relativo é imprescindível para a discussão, haja vista que, tratando-se de ato jurídico nulo, não produtor de efeitos, sequer se precisaria cogitar de responsabilidade civil contratual, mantendo-se o regramento sob a ótica da responsabilidade civil aquiliana) ${ }^{19}$.

O segundo requisito é o descumprimento da obrigação assumida ${ }^{20}$, descumprimento este que se pode dar em caráter absoluto (hipótese na qual se estará diante de inadimplemento

\footnotetext{
${ }^{18}$ Apesar de não ser, textualmente, esse o fundamento dogmático invocado por Sidney Hartung BUARQUE, entende-se ser essa a posição adotada por tal autor, especialmente quando sustenta que "não é o inadimplemento que causa o dano moral, mas as consequências que dele decorrem para o lesado.” (op. Cit., pág. 104).

${ }^{19}$ Neste sentido, André Gustavo Corrêa de ANDRADE, op cit., pág. 136. De outro lado, Fernando NORONHA aponta casos nos quais, mesmo diante de uma relação jurídica negocial, os prejuízos causados entre as partes podem ser regulados pela responsabilidade civil em sentido estrito, como se verifica, p. ex., no caso de responsabilidade pós-contratual, em que os efeitos do contrato continuam a se produzir mesmo após o término da relação (Direito das Obrigações, vol. I, 2a ed., São Paulo, Saraiva, 2007, págs. 446 e ss.).

${ }^{20}$ André Gustavo Corrêa de ANDRADE, op. cit., pág. 136 e R. D. PIZARRO, op. cit., pág. 153/154.
} 
em sentido estrito), em caráter relativo (hipótese na qual se estará diante de mera mora), ou, ainda, na vertente denominada de adimplemento ruim ou violação positiva do contrato ${ }^{21}$.

O terceiro requisito é a existência de um "fator de atribuição de responsabilidade" ao devedor inadimplente, fator este que pode ser subjetivo (dolo ou culpa na execução da obrigação, ou não realização dos chamados melhores esforços, quando se está diante de obrigação de meios, ou, ainda, o não atingimento do resultado prometido, quando se está diante de obrigação típica de resultado) ${ }^{22}$.

O quarto, e mais difícil requisito a se verificar, é justamente a ocorrência de dano moral ressarcível. O problema que aqui se põe é de premissa, decorrente da árdua tarefa de se atribuir, de maneira precisa, o conceito de dano moral (valendo-se, neste ponto, invocar a constatação feita por Antonio JUNQUEIRA DE AZEVEDO no sentido de que, a despeito da intensidade dos trabalhos doutrinários a respeito do tema, ainda não se chegou a uma definição pacífica a respeito de tal conceito $)^{23}$.

Sem nenhuma pretensão de exaustão, acredita-se que os dois grandes posicionamentos no que se refere à conceituação dos danos morais subdivide a doutrina pátria entre [i] aqueles que atribuem a denominação de danos morais às consequências não patrimoniais decorrentes de lesões a direitos da personalidade (entre os quais se destaca Carlos Alberto BITTAR) ${ }^{24}$, conceito este que reputamos mais delimitado, por estabelecer ao menos qual espécie de direito subjetivo deveria ser atingido para que se pudesse cogitar da ocorrência de danos morais ressarcíveis; e, de outro, [ii] aqueles que reputam danos morais todas as consequências prejudiciais de caráter não-patrimonial, conceituando-os por exclusão em disposição assim formulada: "danos morais são todos os prejuízos que não se caracterizariam como patrimoniais" (entre os defensores dessa posição, destaca-se o citado Antonio JUNQUEIRA DE AZEVEDO $)^{25}$.

\footnotetext{
${ }^{21}$ Interessante hipótese de adimplemento ruim é aquela que se dá na aquisição do que Peter SCHLECHTRIEM denomina de ethically tainted goods (ou, em tradução livre, mercadorias eticamente maculadas), tais como bens de consumo fabricados com mão-de-obra escrava, ou, ainda, produtos farmacêuticos desenvolvidos com base em testes em animais (Non-Material Damages: Recovery Under CISG?, in Pace International Law Review, n. 19, 2007, págs. 89/102). É de se imaginar que, em determinadas hipóteses, a aquisição de tais mercadorias pode trazer ao adquirente uma pecha negativa junto ao mercado interno e internacional, prejudicando sua imagem.

${ }^{22}$ André Gustavo Corrêa de ANDRADE, op. cit., pág. 136 e R. D. PIZARRO, op. cit., pág. 154/156.

${ }^{23}$ Cadastros de Restrição ao Crédito (Conceito de Dano Moral), in Estudos e Pareceres de Direito Privado, São Paulo, Saraiva, 2004, pág. 290.

${ }^{24}$ Reparação Civil por Danos Morais, São Paulo, RT, 1993, págs. 29 e ss. Ainda em doutrina, tecendo comentários específicos quanto ao "dano moral contratual", parece ser também esta a posição de Sérgio CAVALIERI FILHO ao prescrever que o inadimplemento poderia dar ensejo à condenação por danos morais se o ilícito também repercutisse na esfera da dignidade da pessoa humana (Programa de Responsabilidade Civil, $6^{\mathrm{a}}$ ed., São Paulo, Malheiros, 2005, págs. 105/106), atingindo, assim, direitos da personalidade.

${ }^{25}$ Cadastros de Restrição ao Crédito (Conceito de Dano Moral), in Estudos e Pareceres de Direito Privado, São Paulo, Saraiva, 2004, pág. 290.
} 
Muito embora, ao menos numa primeira leitura, a conceituação que reputamos delimitada de danos morais pareça conceder subsídios mais precisos para que se verifique a ocorrência de danos morais ressarcíveis em razão do inadimplemento contratual (vez que, por meio dela, poder-se-ia dizer estar diante de "dano moral contratual" quando o descumprimento obrigacional acarretasse, além da violação da prestação, lesão a típicos direitos de personalidade, tais como o direito à vida, à integridade física ou à imagem ${ }^{26}$ ), mesmo ela pode ser alargada para abranger situações mais fluidas e de difícil caracterização, como os componentes do chamado "sistema afetivo" (também reputado como integrante do direito geral de personalidade) $)^{27}$.

Com o intuito de tentar contribuir para a árdua tarefa de se determinar quais eventos dariam ensejo à extração do "dano moral contratual", lança-se mão do conceito de "valoração socialmente típica”, cunhado por M. GAZZARA e trabalhado por R. S. PEREIRA ${ }^{28}$. Trata-se da percepção social de que alguns tipos negociais específicos regram com especial destaque interesses de caráter essencialmente não-patrimonial, razão pela qual o descumprimento das prestações também daria ensejo à condenação do devedor inadimplente ao pagamento de indenização por danos morais. Trata-se de ideia semelhante àquela construída por C. AMATO, no sentido de que, em alguns tipos contratuais, é evidente não apenas a existência de interesses não-patrimoniais subjacentes à prestação, mas, igualmente, sua relevância na operação econômica desejada pelas partes contratantes ${ }^{29}$.

Segundo nos parece, nos casos em que se está diante dos chamados "contratos existenciais" ou "não empresariais" (categoria contratual cunhada, mas pouco desenvolvida, por Antonio JUNQUEIRA DE AZEVEDO, e que, adotando critério nitidamente subjetivo, abarca os casos nos quais ao menos uma das partes contratantes é não-empresária e, com esse contrato, não se objetiva o lucro, celebrando-se lhe para a consecução de interesses nãopatrimoniais. São, assim, exemplos de "contratos existenciais", o contrato de trabalho e o contrato de aquisição da casa própria) ${ }^{30}$, autoriza-se o credor lesado a exigir o pagamento de indenização por danos morais decorrentes do inadimplemento contratual (admitindo-se uma

\footnotetext{
${ }^{26}$ Sobre o tema, cfr. Carlos Alberto BITTAR, Os Direitos da Personalidade, $7^{\mathrm{a}}$ ed., Rio de Janeiro, Forense, 2006, passim.

${ }^{27}$ Sobre o "sistema afetivo", cfr. André Gustavo Corrêa de ANDRADE, op. cit., pág. 141.

${ }^{28}$ R. S. PEREIRA, op. cit., pág. 315.

${ }^{29}$ Il Danno Non Patrimoniale da Contratto, In G. Ponzanelli, Il 'Nuovo' Danno Non Patrimoniale, Padova, CEDAM, 2004, págs. 150/151.

${ }^{30}$ Sobre o tema, cujo desenvolvimento foi interrompido pelo infeliz falecimento de seu autor, cfr. Antonio JUNQUEIRA DE AZEVEDO, Relatório Brasileiro sobre Revisão Contratual Apresentado para as Jornadas Brasileiras da Associação Henri Capitant, in Novos Estudos e Pareceres de Direito Privado, São Paulo, Saraiva, 2009, págs. $185 / 186$.
} 
situação "valoração socialmente típica" quanto à existência e relevância dos interesses não patrimoniais subjacentes à prestação contratualmente assumida).

\title{
5 “DANO MORAL CONTRATUAL" NA JURISPRUDÊNCIA DO SUPERIOR TRIBUNAL DE JUSTIÇA
}

\author{
Ao analisarmos a jurisprudência do Superior Tribunal de Justiça a respeito do tema ${ }^{31}$, é
} possível constatar interessante e sensível evolução. De um início bastante recalcitrante quanto ao cabimento do "dano moral contratual" 32 , passou-se a admitir que, excepcionalmente, e em atenção às circunstâncias do caso, o descumprimento do contrato pode acarretar prejuízos não patrimoniais $^{33}$.

\footnotetext{
${ }^{31}$ Há de se fazer, contudo, importante ressalva de cunho metodológico. Em razão do teor da Súmula 7/STJ (a qual atribui ao STJ nítido caráter de tribunal de teses, e não de fatos, ao prescrever que "a pretensão de simples reexame de prova não enseja recurso especial"), é raro verificar arestos que divirjam da premissa estabelecida pelo Tribunal a quo no que se refere à caracterização, ou não, dos danos morais. Nas hipóteses em que o acórdão recorrido previu textualmente que, à luz dos fatos analisados pelo Tribunal a quo, entendia-se ter, ou não, ocorrido dano moral, a tendência encontrada nos arestos do STJ é a de rejeitar a análise do mérito da questão, invocando a imutabilidade das premissas fáticas fixadas pelo órgão jurisdicional inferior. Nesse sentido: “[...]. No caso sub judice, o Tribunal de origem consignou expressamente estar comprovada a aflição suportada pelo promitentes-compradores e assim a presença dos requisitos necessários à responsabilização da construtora ao pagamento dos danos morais decorrentes do atraso na entrega do imóvel. [...]. Para rever tal conclusão seria imprescindível a incursão na seara probatória dos autos, o que não é permitido nesta instância especial, nos termos da Súmula 7 do STJ. 2. Agravo interno desprovido." (STJ; 4a T.; Ag Int no RESP 1809446/SP; Rel. Min. Marco Buzzi; J. 25/6/2019). Assim seguem diversos acórdãos proferidos pelo Tribunal Superior, dos quais se colaciona, apenas a título exemplificativo, os seguintes: STJ; 4ª T.; Ag Int no RESP 1680119/SP; Rel. Min. Luis Felipe Salomão; J. 7/5/2019; STJ; $3^{\mathrm{a}}$ T.; Ag Int no ARESP 1228249/DF; Rel. Min. Ricardo Villas Bôas Cueva; J. 12/6/2018; STJ; $3^{\mathrm{a}}$ T.; RESP 1758265/PR; Rel. Min. Nancy Andrighi; J. 2/4/2019; STJ; 4 ${ }^{\mathrm{a}}$ T.; Ag. Reg. no ARESP 103684/MA; Rel.: Min. Antônio Carlos Ferreira; J. 21/8/2012; STJ; 4ª T.; Ag. Reg. no ARESP 266709/ DF; Rel.: Min. Isabel Gallotti; J. 11/4/2013; STJ; 4a T.; Ag. Reg. no ARESP 141971/SP; Rel.: Min. Luis Felipe Salomão; J. 24/4/2012 e STJ; 4 ${ }^{\text {a }}$ T.; Ag. Reg. no ARESP 1161069/RJ; Rel.: Min. Luis Felipe Salomão; J. $16 / 2 / 2012$.

${ }^{32}$ Do qual é exemplo o seguinte aresto, da lavra do Min. Sálvio de Figueiredo Teixeira: "I - O inadimplemento do contrato, por si só, pode acarretar danos materiais e indenização por perdas e danos, mas, em regra, não dá margem ao dano moral, que pressupõe ofensa anormal à personalidade. Embora a inobservância das cláusulas contratuais por uma das partes possa trazer desconforto ao outro contratante - e normalmente o traz - trata-se, em princípio, do desconforto a que todos podem estar sujeitos, pela própria vida em sociedade. Com efeito, a dificuldade financeira, ou a quebra da expectativa de receber valores contratados, não tomam a dimensão de constranger a honra ou a intimidade, ressalvadas situações excepcionais." (STJ; 4 ${ }^{\mathrm{a}}$ T.; RESP 202564/RJ; Rel.: Min. Sálvio de Figueiredo Teixeira; J. 2/8/2001). No mesmo sentido seguem muitos outros julgados do fim do Século XX e início do Século XXI, tais como: STJ; $3^{\mathrm{a}}$ T.; RESP 201414/PA; Rel. p/acórdão: Min. Ari Pargendler; J. 20/6/2000 e STJ; 4 ${ }^{\mathrm{a}}$ T.; RESP 338162/MG; Relator: Min. Sálvio de Figueiredo Teixeira; J. 20/11/2001.

${ }^{33}$ A despeito de não se tratar de julgado inovador, seleciona-se, pelo interesse dos debates nele travados, aresto da lavra da Min. Nancy Andrighi, datado de 2010: "Civil. Recurso Especial. Ação de indenização por danos materiais e morais. [...]. Inadimplemento de contrato de compra e venda de casa pré-fabricada. Ausência de mero inadimplemento contratual. Violação ao princípio da dignidade da pessoa humana. Danos morais. Ocorrência. A recorrente celebrou com a recorrida contrato de compra e venda de um 'kit de casa de madeira', pagando-lhe à vista o valor acordado, sendo que, após alguns meses, pouco antes da data prevista para a entrega da casa, a recorrente foi informada, por terceiros, que a recorrida inadimpliu o contrato. - Conquanto a jurisprudência do STJ seja no sentido de que o mero inadimplemento contratual não ocasiona danos morais, tal entendimento, todavia, deve ser excepcionado nas hipóteses em que da própria descrição das circunstâncias que perfazem o ilícito material é possível extrair consequências bastante sérias de cunho psicológico, que são resultado direto do
} 
Uma vez admitida a condenação, ainda que em caráter excepcional, o Superior Tribunal de Justiça passou a enumerar uma série de casos (os quais, consoante de verifica, trata-se, em sua quase totalidade, de "contratos existenciais") nos quais se passou a entender devida a condenação ao pagamento do "dano moral contratual", admitindo-se, em determinadas hipóteses, até mesmo a caracterização do dano moral in re ipsa (do que se denota uma interpretação bastante assemelhada à ideia de "valoração socialmente típica"; vale dizer: em determinados tipos contratuais, entende-se que o inadimplemento em sentido lato dá ensejo à condenação por danos morais, ainda que tal sorte de prejuízo não reste cabalmente comprovada na hipótese) $)^{34}$.

Desta feita, entende-se cabível a condenação ao pagamento de "dano moral contratual" em casos nos quais se constata: [i] o atraso na conclusão das obras de apartamento em condomínio edilício, especialmente se o atraso persistiu por período de tempo particularmente alongado $^{35}$ : [ii] de cancelamento de voo em razão do chamado overbooking ${ }^{36}$;

inadimplemento culposo. - No presente processo, o pedido de compensação por danos morais declinado pela recorrente não tem como causa o simples inadimplemento contratual, mas também do fato de a recorrida ter fechado suas instalações no local da contratação (Estado do Rio de Janeiro) sem the dar quaisquer explicações a respeito de seu novo endereço e/ou da não construção do imóvel. - Essa particularidade é relevante, pois, após a recorrente ter frustrado o seu direito de moradia, pelo inadimplemento do contrato de compra e venda de casa pré-moldada, o descaso da recorrida agravou a situação de angústia da recorrente. - A conduta da recorrida violou, portanto, o princípio da dignidade da pessoa humana, pois o direito de moradia, entre outros direitos sociais, visa à promoção de cada um dos componentes do Estado, com o insigne propósito instrumental de tornálos aptos de realizar os atributos de sua personalidade e afirmar a sua dignidade como pessoa humana. - Diante dessas circunstâncias que evolveram o inadimplemento contratual, é de se reconhecer, excepcionalmente, a ocorrência de danos morais. Recurso especial conhecido e parcialmente provido." (STJ; $3^{\text {a }}$ T.; RESP 1025665/RJ; Rel.: Min. Nancy Andrighi; J. 23/3/2010).

${ }^{34}$ Milena Donato OLIVA aponta a pouca utilidade da regra geral estabelecida pelo STJ quanto à não indenização de danos morais decorrentes do inadimplemento contratual, sustentando que a existência de inúmeras exceções não traz luz à matéria. Ideal, segundo a autora, seria atribuir maior relevância ao interesse juridicamente tutelado (op. cit., págs. 13/28).

35 “[ [...]. 2. O inadimplemento contratual, consubstanciado no atraso na entrega do imóvel, não é capaz, por si só, de gerar dano moral indenizável. Precedentes. 3. Hipótese em que foi reconhecida pelo Tribunal de origem a existência de circunstância excepcional a ensejar a reparação por danos morais - fixados em $\mathrm{R} \$ 5.000,00$ (cinco mil reais) -, tendo em vista que o atraso na entrega do imóvel foi de mais de dois anos, e somente ocorreu após decisão judicial liminar, extrapolando, assim, o mero aborrecimento resultante do descumprimento contratual." (STJ; 4 $4^{\mathrm{a}}$ T.; Ag Int no ARESP 1366092/ES; Rel. Min. Eaul Araújo; J. 18/6/2019). No mesmo sentido, cfr. STJ; $4^{\mathrm{a}}$ T.; Ag. Reg. no RESP 725.864/PR; Relatora: Min. Maria Isabel Gallotti; J. 21/8/2012 e STJ; $4^{\mathrm{a}}$ T.; RESP 830572/RJ; Rel.: Min. Luis Felipe Salomão; J. 17/5/2011. Em sentido contrário, inadmitindo a condenação ao pagamento do "dano moral contratual" nessa hipótese, especialmente quando o atraso na conclusão das obras não se mostrou expressivo, cfr. STJ; $4^{\mathrm{a}}$ T.; Ag. Reg. no ARESP 546608/RJ; Rel.: Min. Maria Isabel Gallotti; J. 3/5/2012; STJ; $3^{\text {a }}$ T.; Ag. Reg. no RESP 1179336/RJ; Rel.: Min. Paulo de Tarso Sanseverino; J. 16/10/2012; STJ; 4 ${ }^{\mathrm{a}}$ T.; RESP 876527/RJ; Rel.: Min. João Otávio de Noronha; J. 1/4/2008 e STJ; 4 ${ }^{\mathrm{a}}$ T.; RESP 712469/PR; Relator: Min. Aldir Passarinho Jr.; J. 13/12/2005.

36 "RECURSO ESPECIAL. AÇÃO DE INDENIZAÇÃO POR DANO MORAL. [...]. OVERBOOKING [...]. DANO MORAL. VERIFICAÇÃO [...]. III - É possível aferir todo o constrangimento suportado pelo ora recorrido, que se iniciou perante os funcionários da companhia, para conseguir embarcar na aeronave, prosseguiu, na constatação de que seu assento por outra pessoa estava ocupado, e culminou com sua indevida acomodação na cabine dos pilotos, frustrando, inequivocamente, todas as expectativas naturais que o contrato de transporte pode gerar ao passageiro; [...]. VI - Recurso Especial parcialmente provido." (STJ; 3 ${ }^{\text {a }}$ T.; RESP 
[iii] descumprimento do contrato de ensino (caso no qual o curso de pós-graduação oferecido sequer era reconhecido pelo Ministério da Educação, inapto, portanto, a assegurar o título de pós-graduado ao aluno contratante) ${ }^{37}$; ou, ainda, [iv] de recusa de cobertura de seguro-saúde ou plano de saúde ${ }^{38}$.

Por derradeiro, vale ressaltar o interessante caso se verificou no julgamento do RESP 1255315/SP, relatado pela Min. Nancy Andrighi, em que o "dano moral contratual” se deu no bojo de verdadeiro "contrato empresarial". Tratou-se de abuso do direito potestativo de resilição, com a realização de condutas que, além das consequências patrimoniais, acarretaram lesão à imagem empresarial do distribuidor ${ }^{39}$.

\section{CONCLUSÕES}

A questão atinente ao chamado "dano moral contratual", a despeito de atual e relevante, ainda está a despertar atenção mais detida por parte da doutrina brasileira.

Contra a admissão da reparação de danos morais em decorrência do inadimplemento contratual, levantam-se em geral três argumentos: [i] a separação estanque entre os regimes ressarcitórios da responsabilidade contratual e responsabilidade aquiliana; [ii] o caráter necessariamente patrimonial da prestação (de cujo inadimplemento resultariam prejuízos

750128/RS; Rel.: Min. Massami Uyeda; J. 5/5/2009).

${ }_{37}$ "CIVIL. AÇÃO INDENIZATÓRIA. CURSO DE MESTRADO NÃO RECONHECIDO PELO MEC/CAPES. PRETENSÃO DE DANOS MORAIS, MATERIAIS E LUCROS CESSANTES. DEFERIMENTO DO PRIMEIRO. IMPROCEDÊNCIA DOS DEMAIS. SÚMULA N. 7 - STJ. I. Devido o dano moral pela frustração na obtenção de diploma de mestrado devido ao não reconhecimento do curso oferecido pela instituição de ensino ré perante o Ministério da Educação. II. [...]. IV. Recursos especiais não conhecidos." (STJ; 4 T.; RESP 998265/RO; Relator: Min. Aldir Passarinho Jr.; J. 14.04.2010).

${ }^{38}$ Trata-se de caso bastante recorrente na jurisprudência do STJ, objeto de inúmeros arestos, dos quais se destaca: "A recusa indevida/injustificada, pela operadora de plano de saúde, em autorizar a cobertura financeira de tratamento médico a que esteja legal ou contratualmente obrigada, enseja reparação a título de dano moral, por agravar a situação de aflição psicológica e de angústia no espírito do beneficiário. Precedentes." (STJ; $3^{\mathrm{a}}$ T.; Ag Int no ARESP 1785118/SP; Rel. Min. Nancy Andrighi; J. 27/5/2019). No mesmo sentido, cfr. STJ; $3^{\mathrm{a}}$ T.; Ag Int no ARESP 1406287/PR; Rel. Min. Moura Ribeiro; J. 15/4/2019; STJ; 3a T.; RESP 1757938/DF; Rel. Min. Ricardo Villas Bôas Cueva; J. 5/2/2019; STJ; $3^{\text {a }}$ T.; RESP 1289998/AL; Rel.: Min. Nancy Andrighi; J.

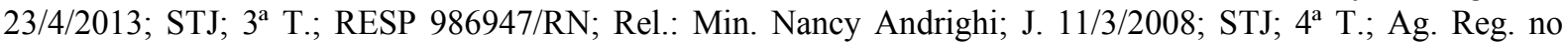
ARESP 213169/RS; Rel.: Min. Luís Felipe Salomão; J. 4/10/2012; STJ; $3^{\mathrm{a}}$ T.; Ag. Reg. no RESP 1254952/SC; Rel.: Min. Sidnei Benetti; J. 15/9/2011.

39 "CIVIL E PROCESSO CIVIL. CONTRATOS. DISTRIBUIÇÃO. CELEBRAÇ̃̃O VERBAL. POSSIBILIDADE. LIMITES. RESCISÃO IMOTIVADA. BOA-FÉ OBJETIVA, FUNÇÃO SOCIAL DO CONTRATO E RESPONSABILIDADE PÓS-CONTRATUAL. VIOLAÇÃO. INDENIZAÇÃO. CABIMENTO. DANOS MORAIS E HONORÁRIOS ADVOCATÍCIOS. REVISÃO. POSSIBILIDADE, DESDE QUE FIXADOS EM VALOR IRRISÓRIO OU EXORBITANTE. SUCUMBÊNCIA. DISTRIBUIÇÃO. CRITÉRIOS. 1. [...]. 4. A rescisão imotivada do contrato, em especial quando efetivada por meio de conduta desleal e abusiva - violadora dos princípios da boa-fé objetiva, da função social do contrato e da responsabilidade pós-contratual - confere à parte prejudicada o direito à indenização por danos materiais e morais.” (STJ; $3^{\mathrm{a}}$ T.; RESP 1255315/SP; Relatora: Min. Nancy Andrighi; J. 13.09.2011) 
exclusivamente patrimoniais) e, ainda, [iii] o necessário desestímulo à "indústria do dano moral".

De outro lado, são também três os subsídios dogmáticos para a admissão do "dano moral contratual": [i] a distinção entre ato ilícito relativo e ato ilícito absoluto; [ii] a compreensão de que a prestação pode corresponder a um interesse não-patrimonial do credor (cuja violação pode acarretar o surgimento de danos extrapatrimoniais); e, ainda, [iii] a distinção doutrinária entre dano-evento e dano-prejuízo.

O recurso a esses subsídios dogmáticos permite concluir pela ressarcibilidade do dano moral decorrente do inadimplemento do contrato quanto se estiver diante de ao menos quatro requisitos: [i] a preexistência de uma relação de direito relativo; [ii] o inadimplemento (relativo, absoluto ou mal adimplemento) de uma obrigação; [iii] a existência de um "fator de atribuição de responsabilidade" e, por derradeiro, [iv] a caracterização de dano moral ressarcível.

À luz desses requisitos, a jurisprudência do Superior Tribunal de Justiça ultrapassou um primeiro momento de recalcitrância quanto à admissibilidade do "dano moral contratual" para passar a admiti-lo, especialmente quando se está diante de contratos nos quais sobressai a relevância dos interesses não patrimoniais do credor (contratos estes qualificáveis sob a rubrica de "contratos existenciais").

\section{REFERÊNCIAS}

AMATO, Cristina. Il Danno Non Patrimoniale da Contratto, In: G. Ponzanelli, Il 'Nuovo' Danno Non Patrimoniale. Padova: CEDAM, 2004, p. 141-162.

ANDRADE, André Gustavo Corrêa de. Dano Moral em Caso de Descumprimento de Obrigação Contratual. Revista da EMERJ, vol. 8, n. 29, 2005, p. 134-148.

ANTUNES VARELA, João de Matos. Das Obrigações em Geral, vol. I, 10. ed. Coimbra: Almedina, 2000.

BITTAR, Carlos Alberto. Reparação Civil por Danos Morais. São Paulo: RT, 1993.

BITTAR, Carlos Alberto. Os Direitos da Personalidade, 7. ed. Rio de Janeiro: Forense, 2006.

BUARQUE, Sidney Hartung. Da Demanda por Dano Moral na Inexecução das Obrigações. 2. ed. Rio de Janeiro: Forense, 2007. 
CORDEIRO, Carolina Souza; SANTANA, Hector Valverde. Dano Moral Decorrente de Inadimplemento Contratual de Plano Privado de Assistência à Saúde. Revista de Direito do Consumidor, ano 20, vol. 80, out.-dez./2011, p. 213-234.

FERRANDIN, Mauro. Dano Moral Contratual. In: Jurisprudência Catarinense, ano XXXII, n.110, 2006, p. 181-207.

ITURRASPE, Jorge Mosset; PIEDECASAS, Miguel A. Responsabilidad Civil y Contratos: Responsabilidad Contractual. Buenos Aires: Rubinzal, 2007.

JUNQUEIRA DE AZEVEDO, Antonio. Cadastros de Restrição ao Crédito (Conceito de Dano Moral). In: Estudos e Pareceres de Direito Privado. São Paulo: Saraiva, 2004, p. 289299.

JUNQUEIRA DE AZEVEDO, Antonio. Por Uma Nova Categoria de Dano na Responsabilidade Civil: O Dano Social. In: Novos Estudos e Pareceres de Direito Privado, p. 377-384.

JUNQUEIRA DE AZEVEDO, Antonio. Relatório Brasileiro sobre Revisão Contratual Apresentado para as Jornadas Brasileiras da Associação Henri Capitant. In: Novos Estudos e Pareceres de Direito Privado. São Paulo: Saraiva, 2009, p. 185-186.

LIMA, Alvino. Culpa e Risco. 2. ed. São Paulo: RT, 1998.

MELLO, Marcos Bernardes. Teoria do Fato Jurídico (Plano da Existência). 14. ed. São Paulo: Saraiva, 2007.

MORAIS, Fabíola. Aproximação do Direito Contratual dos Estados-Membros da União Européia. Rio de Janeiro: Renovar, 2007.

NORONHA, Fernando. Direito das Obrigações, Vol. I. 2. ed. São Paulo, Saraiva, 2007.

PATRÍCIO, Miguel Carlos Teixeira. Análise Económica da Litigância. Coimbra: Almedina, 2005.

PEREIRA, Rui Soares. A Responsabilidade por Danos Não Patrimoniais do Incumprimento das Obrigações no Direito Civil Português. Coimbra: Coimbra, 2009.

PIZARRO, Ramón Daniel. Daño Moral (Prevención, Reparación, Punición). Buenos Aires: Hammurabi, 1996.

SCHLECHTRIEM, Peter. Non-Material Damages: Recovery Under CISG? Pace International Law Review, n. 19, 2007, p. 89-102.

SCHREIBER, Anderson. Novos Paradigmas da Responsabilidade Civil: Da Erosão dos Filtros da Reparação à Diluição dos Danos. São Paulo: Atlas, 2009. 


\section{DADOS DA PUBLICAÇÃO}

Categoria: artigo submetido ao double-blind review.

Recebido em: 05/08/2019.

Aceito em: 17/07/2020 
